\title{
Poverty and Fertility: Reproductive Change under Persistent Poverty
}

\author{
BERTIL EGERÖ
}

Sociologist and Demographer

PROP - Programme on Population and Development

Department of Sociology, University of Lund

Lund, Sweden

\begin{abstract}
In recent contributions to the discussion of fertility change in poor societies, two main lines of interpretation can be identified, the "materialist" and the "ideational" respectively. While the former emphasizes economic and security factors as prime causes of reproductive patterns and changes, the latter stresses the importance of diffusion of ideas and norms. The ideational perspective supports "supply side" policies for fertility decline, while the materialist perspective lends support to a more indirect welfare or "demand" side orientation to population policy.

Bangladesh belongs to a group of countries with persistent and widespread poverty where the beginnings of fertility decline have now been recorded. The absence of any visibly significant socioeconomic changes for its rural majority has been used to justify claims that family planning activities have an independent effect on fertility. The paper draws together available evidence on the circumstances of rural life in Bangladesh. Taken together, the evidence is that changes have occurred in social relations in the household, brought about by economic crisis and in turn enabling changes in childbearing.

The Bangladesh evidence confirms the difficulties encountered on a conceptual level in trying to maintain a distinction between materialist and ideational approaches to fertility analysis. The distinction between the two lines is unclear, and upholding it could be counterproductive to advances in the understanding of fertility change.
\end{abstract}

Keywords: poverty, fertility decline, value of children, society, gender relations, Bangladesh

\section{Background and purpose}

It is now many years since the label Less Developed Countries (LDCs) was accepted as an appropriate description of some countries in the South. Economic development over the last two decades has led to a growing differentiation both between and within these countries. A good number of the former LDC countries are now successful competitors on the international market.

The differences are equally significant in the area of demographic dynamics. The most advanced countries in the South (South Korea, Taiwan, and others) are now about 
to end their demographic transition with fertility levels of 2 children or less per woman, the replacement level where population numbers in the long run will stabilize.

Pockets of poverty remain in these countries, as well as in the wealthiest nations of the world. But the least successful countries in the South are profoundly affected by widespread rural as well as urban poverty. Poverty affects households, individuals and the public sector, which by and large is unable to provide services to strengthen the human capital required for economic advancement. In the poorest countries, the demographic transition is proceeding slowly. While death rates have fallen, birth rates remain high. The result is stable high rates of population increase.

Between these extremes one finds a variety of countries, e.g. India, with fair economic prospects and a distinct movement towards smaller families, but still facing many years of population increase. Poverty is widespread also in this group of countries, and there are no signs that it will be eliminated, or even significantly reduced in absolute numbers, in the short or medium term.

The future of the population momentum in the South is very much linked to the poverty question. Poor people tend to have more children than those better off. There are, however, clear variations in fertility levels even among the poor, and a movement towards smaller families has been shown to occur under conditions of apparently persistent poverty. Similar findings have been presented from Europe's modern history.

The present study focuses on relations between poverty and fertility in countries where fertility is still high. It does not primarily address the relation between poverty and demographic patterns. Higher mortality is normally part of poverty, in fact mortality is sometimes used as an index of poverty. A few words will be spent on fertility differences and whether the poor are known to have more children than the non-poor.

The cause-effect relation between poverty and fertility levels, important as it may be, is dealt with only briefly in the report. On the macro level it is a complex issue: There is no straight relation between income level in society and fertility, in particular if more wealthy countries in the South are excluded (see Figure 1). Nor is there any direct correlation between per capita GDP rate of growth and rate of population increase (see Figure 2).

Of the many different questions that may be asked about poverty and fertility, the study concentrates on one particular set: fertility change or non-change under condi-

Fi g u r e 1. Fertility in relation to income in developing countries, ca 1980.



Source: Birdsall 1988 
Fig u re 2. Income per capita growth and population growth, developing countries, 1970-81.

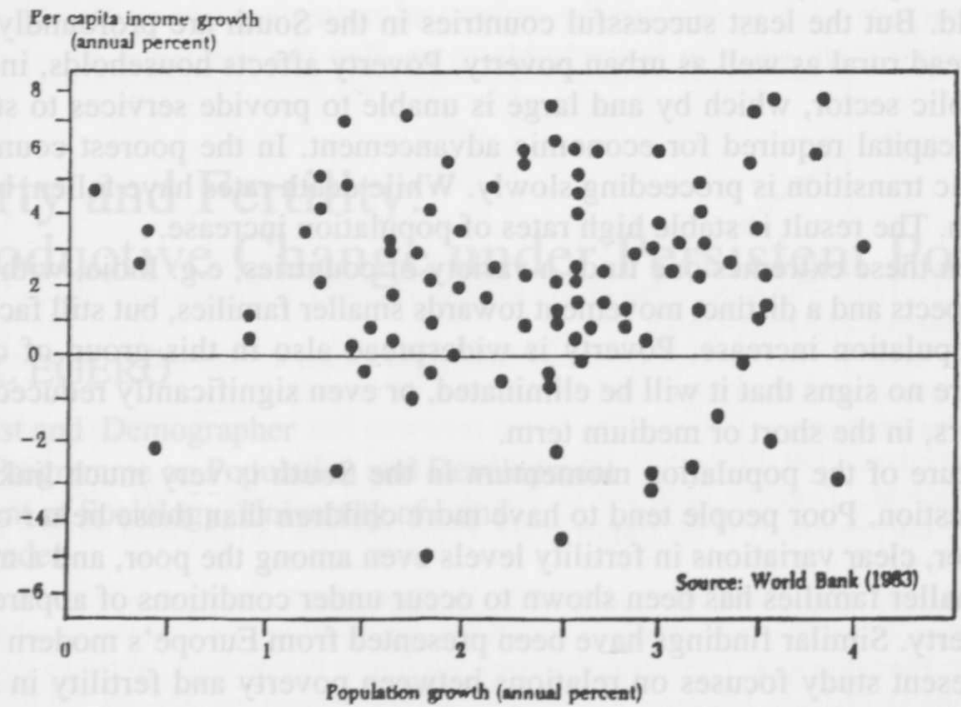

tions of poverty. "Poverty" is in itself nothing static - poverty states change in relation to other changes in the wider society. Thus, when we talk about fertility change under poverty, the poverty context itself and its dynamics need to be dealt with.

One country has, more than any others, come to serve as a testing ground for projects, studies and debates over the links between development and reproduction Bangladesh. Scientists convinced that socioeconomic improvements are necessary for a change to smaller families have long maintained that the pervasive poverty, illiteracy and insecurity under which the majority of its inhabitants live are effective constraints against any significant change. But now there are indications that a change has begun. Fertility rates have declined so much during the 1980 s that a distinct downward trend is in evidence.

This has lead to a series of scientific reports and mass media publicity presenting Bangladesh as the best proof that family planning can change fertility, even in the absence of improvements in the conditions under which people live. Knowledge about the details of the trend, for instance how it is manifested among different socioeconomic groups of people, is still limited. Nor is there as yet much data linking fertility changes to other changes in Bangladeshi society. But the amount of scientific studies relevant to Bangladeshi fertility change is sufficient to permit a scrutiny of the arguments over the role of family planning versus material change. This is what makes Bangladesh a good case for the present study.

\section{Poverty, wealth, and fertility}

In the general opinion, poor people on the whole have more children than the more well-to-do. If we accept this as a rule, there certainly are exceptions. In the first decades of independence in Sub-Saharan Africa, the new urban elites were known for their big families. In the first decade or so, it must have extended far beyond the elite. Studies 
in some countries showed that fertility levels could be at least as high in urban as in rural areas. Children were an expression of wealth. Free schooling, free health care, subsidized housing and food help keep costs down. Then why should the urban middle class abstain?

Big families are in no way exclusively the privilege of African elites. The American Kennedy family tradition is matched by similar tendencies among the resourcerich in India and other countries in the South. But further down the social ladder, one recognized motive for a smaller family size is the aspiration to climb, socially and economically. Young rural people who get an education often begin to aspire for another life than that of the small-scale farmer. They search for ways to make money, and may increasingly perceive children as an opportunity cost to be balanced against other ways of spending. Their aspirations may also extend to the offspring itself. They may choose "quality" - a few well-educated children - before a larger number of children with less schooling.

Living conditions may deteriorate, as has happened especially in urban areas in Africa. Whether people respond by having fewer children depends on their position, perspectives and expectations. We may talk about 'defensive motivation' to express parents' desire to have fewer children in times of hardship. This happened in the 1950s in South Korea, where parents were strongly committed to giving their children a good start, not least through education (Tai Hwan 1993). The economic difficulties led many to choose a small family. A similar process is believed to be underway in Kenya, where fertility has fallen during the 1980s (Egerö and Mburugu 1994). But it did not happen in Costa Rica during the economic recession around 1980 (Dierckxsens 1994). Fertility had been declining for well over a decade, but during the recession it increased again, at least temporarily. Generalizations require great caution. Local conditions may exert unexpected influences.

But do the poor really have more children than the non-poor, as is so often heard? In affluent countries of today, obviously no. There the average number of children born to each woman is two or less, a figure too low to be achieved unless all numerically important social groups are fairly close to the average. What about less affluent countries? Gerry Rogers $(1989,8)$ summarizes the evidence from studies of Bangladesh, India, Nepal, and Pakistan: "There is no evidence in the studies in this book that the poor have relatively high fertility, and there is a hint that their fertility may be lower than [that of] middle income groups at least".

Fertility levels vary even between poor households in the same society. In some contexts, having many children is an asset to the household. Krishna Ghimire (1993) finds that large migrant families to a newly colonized area in Costa Rica are better off than the smaller families. Rafiqul Chaudhury (1989) presents data from rural Bangladesh in the 1970 s, showing a strong positive correlation between family size and land holding per capita. Where family labor matters, few children means more poverty.

This picture contrasts with the picture of children as costs given, for instance, by Bauer and Mason (1993). In their studies of the Philippines and Thailand, the authors depart from an outright assumption that family size has an adverse impact on child welfare, and even conclude that "children in larger families do face substantially elevated risks of poverty" (ibid., 15). Such a result would be consistent with an urban situation where child labor is prohibited, children contribute minimally in the family and family income derives only from the employment of the adult members. Most poor in most countries in the South are far from this situation.

Studies showing that the poorest of the poor have small families are not unusual. But there is no unequivocal interpretation of cause-effect links behind such a finding, or even whether it reflects conscious choice or not. Nor is the picture the same everywhere. We will return to this issue later in the report. 


\section{Poverty and fertility decline - the European experience}

Early studies of the demographic transition in Europe were based on national statistics. A simple pattern emerged, which could be interpreted as a fall in mortality setting in motion a similar trend in fertility. As research was extended to local communities or social strata, more complex patterns of change were found, which made any general statements about the process difficult.

Studies of current patterns and trends in non-European countries show a similar complexity. The demographic transition is a historical process increasingly known in its details but with little consensus on how to interpret the circumstances around fertility declines.

Human reproduction during pre-transition periods was in no way uniform in all societies. Local European communities have been found to adjust childbearing according to good or bad times (Wrigley 1969). Others have been characterized by what Louis Henry (1961) called "natural fertility", a lack of conscious family size limitation. Even in these societies, however, social customs for regulating spacing of pregnancies have been found to vary so much that the final number of children per woman could still be quite different.

A general view of the European change to small families during the last hundred years is that it was part of a general improvement in living standards, a change to wage employment, and urban life. Such changes were certainly there and influenced the process. What is less well-known is that fertility declines took place also in communities which were rural and based on agriculture, even in conditions of poverty. What were then the conditions for such a change to take place?

One of the chief investigators of the European experience, Ansley Coale (1973), has summarized the conditions for fertility decline in three short sentences:

- that the regulation of offspring is perceived as within the realm of conscious calculus of choice,

- that means for regulation are known and acceptable (by self and community) and

- that fewer children would be an advantage.

Even if these three conditions are sufficient for a sustained decline in fertility, they themselves imply a considerable social change. The first condition refers to secularization - education, communication, and the weakening of the power of dominant ideologies like religion. In terms of the second, means such as coitus interruptus are likely to have been known and practiced in Europe long before the slow fertility decline began. Modern contraceptive technology played an insignificant role.

The question of motivation remains: What circumstances made women (and their men, or family) want to have increasingly fewer children, down to one or two, or even no children at all?

\section{Fertility trends - two main lines of explanation and policy}

The demographic transition normally begins with a fall in mortality. In particular, infants and young children run less risk of dying. Originally it was believed that this change would in itself result in falling birth rates. But the relation was found to be much more complex, with fertility falling sometimes simultaneously with mortality, sometimes even preceding it. This led to an interest in the roles of children in the life of a family - economically as well as socially. Many scientists saw childbearing as a rational calculus of costs and benefits, especially in societies drawn into "moderniza- 
tion". The challenge was to identify the factors included in such calculus, and how various conditions of life, especially the material, would affect motivations for many or few children.

A different strand of social science research developed in line with the growing international engagement in programs to influence fertility trends. As growing aid resources were spent on supplies of modern contraceptives and efforts to convince rural families to use them, policy-oriented research was needed in order to raise the efficiency of such investments. The intellectual framework for this research was based on the existence of "latent demand" - for fewer children and therefore for modern contraception. Such demand could remain subconscious because of pro-natalist traditions from times when the loss of one or more children was a fact of life, safe-guarded by having many children. The change to a state of generally improved health and survival was gradual and diffuse, creating a "latent" rather than a conscious demand.

This line of thought is commonly called "ideational", as contrasted with the "materialist" line already mentioned. The name derives from the notion that the idea to stop child-bearing when a certain number of children is born is in no way common to mankind. In some societies this would be a new idea, a kind of social innovation. Thus, what is required is a new perception, that a certain number of children is enough. If modern contraceptives were introduced and made socially acceptable, the new perception would lead more and more people to use them and fertility would decline.

At the theoretical level, the "materialist" and the "ideational" streams of thought may in fact not be so far apart. They both see fertility change as a result of changed perceptions of what is taking place. These perceptions are formed through social communication and interaction. Cultural factors are obviously relevant in this process. This has led some writers to argue that the "materialist" and the "ideational" schools of thought complement each other. Both are needed for a more complete interpretation of fertility patterns and trends. But important differences appear in their policy conclusions for achieving lower levels of fertility. From an ideational perspective, the recommendations are to ensure a good supply of contraceptives, supplemented by information, education and communication (IEC). By contrast, a materialist analysis leads to identification of policies whose direct and indirect effects on people's living conditions influence the demand for children, and to policies which widen their options to choose accordingly. Such policies search to address changes towards better social and economic security, gender equality, education and free information.

The latter policy could be said to be oriented towards people's demands, while the former would primarily deal with issues of supply.

\section{The value of children - a correct question?}

An explanation of why people have many or few children could be sought in what the children give to their parents, or are expected by them to give. For parents in affluent countries, a child may have a great emotional value. Most likely, they also expect that their child will give them social support when they grow old. For a poor farming household, the child is a potential or real contribution to the labor force required on the farm. In the first case, one or two children would be enough, in the second additional children are often welcome.

Discussing the European experience, Susan Greenhalgh $(1990,85)$ summarizes what she sees as the common denominator of the fertility decline: "...alterations in the value of children in the class-specific family economy". She elaborates: "Political developments, such as the adoption of laws making school attendance compulsory and restricting child labor in factories, were crucial instigators of fertility change, underscoring 
the importance of political and legal forces that lie outside the purview of conventional theory".

This interpretation is based on a very important assumption - that poor people have a certain number of children because they need them. Evidence from 18 th century Sweden seems to support this view. Families in Bergslagen had many children, while the lowland farmers closer to Mälaren had few. In Bergslagen, many hands were required to work in mining and forestry. Among the farmers, few children was a necessary precaution against the risk that the farmland would have to be divided.

Such interpretations of historical differences in Sweden, like explanations of fertility differences in poor countries today, build on the idea that parents are motivated to choose a particular family size by the value of children in the family. What does this mean, more precisely, and how can it be measured?

John Caldwell (1982) has presented a general theory of fertility, built on what he calls intergenerational wealth flows from old to young and from young to old. The newborn child is entirely dependent on its parents and other adults for its survival. As time goes, it can undertake increasingly valuable tasks. In smallholder agriculture, young children may herd the cattle, or collect water and firewood. When school becomes compulsory or something the farmers want for their children, the relation changes; children spend years in school, supported by the adults and unable to contribute to the household in the short run. The more postponed and uncertain the returns from children are, the less motivated the parents may become to have many children.

Caldwell has spent many years in research in Sub-Saharan Africa, in areas where children belong to and are cared for by wider kin networks, and where the general perception is that many children are a great value. These networks gradually give way to nuclear family formations, a modernization process which Caldwell regards as necessary for radical reductions in childbearing. When the costs to bring up a child are more directly carried by the parents themselves, they are likely to change their perception of the costs. And, just like they themselves have loosened the ties to their parents and kin, so they have to face growing uncertainties whether their own children will in fact give them any support in the days of old age.

To measure the value of children in a concrete social setting raises a series of problems. Mead Cain and his colleagues have studied rural Bangladeshi villages in the 1970s (Cain et al. 1981; Cain 1983). He focused on fertility in the light of what he called risk and insurance. In terms of risk, he found that "safety first" was the basic principle among small farmers; they may try to maximize net returns, but even more important to them was to minimize the risk of disaster, including temporary crises, for instance when an adult fell sick. Children were seen as a means to handle such crises. The insurance side was no less important: the contribution children were expected to give as security in the old age of their parents.

Cain's studies have been followed by a range of surveys trying to catch the meaning of "children's value" in the everyday life of poor people. The difficulties met by the researchers show, if anything, that it must be a complex matter even for the parents concerned. One respected student of South Asia, Tim Dyson $(1991,81)$, appears to reject the whole approach, proposing that "children work because people have children, rather than people have children because children work". There is a risk inherent in the terminology - some may take the "calculating the value of children" too literately. Like Karen Oppenheim Mason (1992), we find that the concept itself is meaningful. But there is no simple way either for parents or for researchers to weigh children's contributions today, and those they are expected to give in the future, in any simple income scale. For instance, all the little errands and other tasks children can do can hardly be measured in economic terms. Yet, "without children to perform this work, the total productivity of the household suffers significantly" (ibid., 8). 
Given this complexity, the way parents' perceptions change must also be diffuse, linked as they are to a social exchange within the community on the value of many or few children as conditions change.

\section{Bangladesh - a case study}

Ever since the 1970 s, a growing number of studies have been published on different aspects of rural life in Bangladesh. Some of them were linked to a plan termed the Matlab project, started by the New York-based Population Council in the 1970s with the aim to study and improve on ways to increase the use of contraceptives in a rural context.

Among the more recent studies of fertility trends in Bangladesh, we rely in this report mainly on a World Bank study made by John Cleland et al. and published in 1994 (here called Cleland et al. 1994). This study is in the research tradition we earlier described as "ideational", and concludes that improved access to family planning and contraceptive use is the main vehicle behind lower fertility. There are many studies representing the "materialist" research tradition, and Naila Kabeer's (1994) examination of the Cleland report is one of the more important texts used here. These are supplemented by rural poverty studies such as the ambitious collection edited by Rahman and Hossain (1992). A full listing of the sources consulted is found at the end of the report.

\section{Bangladesh - the country}

"Before Robert Clive led the army of the British East India Company against the Nawab of Bengal in 1757, Eastern Bengal (now Bangladesh) was a land of plenty, perhaps the wealthiest place on Earth. By the early years of the following century its demise was almost complete. Military subjugation, economic plunder, and cultural destruction and degradation have left Bangladesh permanently defenseless..." (Thomas 1993).

Bangladesh is one of the poorest countries of the world. It is also one of the most densely populated countries, with close to 800 inhabitants per square kilometer on an area only about a third of Sweden. Demographic projections of current trends - not to be mistaken for predictions - bring its population up to twice its current number (120 million 1992) within 25 years (UNDP 1994).

Bangladesh consists mainly of lowland areas surrounding the Ganges, Brahmaputra and Kalini rivers. Its rich land is fertilized through the recurrent flooding of the rivers. Closer to the Indian Ocean, the rivers form a huge delta where agriculture as well as aquaculture contribute to the well-being of its inhabitants. Bangladesh is predominantly rural with $82 \%$ of the population living in rural areas in 1992 compared with $85 \%$ in 1981(UNDP 1994). Close to $50 \%$ of the urban population is concentrated in the two biggest cities, the capital Dhaka ( 7.4 mil.) and Chittagong (2.3 mil.) (UN 1994). In many parts of the country the urban-rural division is blurred due to very high population densities.

The coastline of Bangladesh is long, densely populated and with traditionally good fishing. Nowadays, the coastal communities live under the threat not only from tractionaf hazards such as cyclones, but also from such human forces as entrepreneurs keen on commercial exploitation of mangrove areas and coastal waters.

Industrialization is not very advanced in Bangladesh, but accelerated during the 1980 s through the fast expansion of garment and other export-processing manufactur- 
ing (Feldman 1992). The economy is still dominated by smallholder agriculture and fishing. However, agriculture had reduced its share of the labor force from close to $85 \%$ in 1965 to $59 \%$ in the early 1990 s, while manufacturing and services increased to $13 \%$ and $28 \%$ (UNDP 1994).

The modern history of Bangladesh is one of endemic poverty, famines, and a growing number of inhabitants. The depth of poverty is not only the everyday misery, it also entails a high level of vulnerability to crisis. While natural disasters mean starvation for millions, for the individual household the sickness of one member may bring it permanently down below the poverty line. Around $40 \%$ of the rural population lives in poverty, of these about $40 \%$ are the "hard-core poor" reaching no more than twothirds of the poverty line (Rahman and Hossain 1992). Vast urban slums have developed over the past decades, carrying evidence of the rural plight.

\section{Dynamics of population change}

Like other ex-colonies, Bangladesh has undergone a profound transformation during the twentieth century. One of the outstanding features of this change is the dramatic improvement in life expectancy and health. The threat of death today is nowhere near what it was around 1900. All historical estimates are hazardous, but scientists seem to agree that a person born in 1900 could expect to live on the average about 20 years. A woman who had seven children could expect less than three of them to reach adulthood. By 1960 , life expectancy was close to 50 years, and five of the seven children reached adult age (Cleland et al. 1994).

The mortality decline started before World War II and, with temporary setbacks, continued right to the present day. Fertility shows a different pattern of change. International statistics display a rise in fertility from at least the 1950 s to the mid-1970s, when it is estimated to have been over 7 children per married woman ${ }^{1}$. What brings a new dimension to the situation in Bangladesh is that in this poor society people are beginning to search for new family models. Signs of the change began to emerge towards the end of the 1970 s. It is now estimated that by 1990 the national fertility level had gone down to 5 children or below.

The fertility rates demographers use to describe such changes are hypothetical measures, constructed to reflect the reproductive patterns of women in different ages at $a$ given point in time. The decline is not immediately reflected in the crude birth rate for Bangladesh, which is kept up by the still growing new generations of young women who enter into marriage and have their first children. The age distribution of the population of Bangladesh contains a growth momentum, through the many young would-be parents, and through the trend that more of them will live on into old age. In this respect, further population increase for many years is inevitable, even if people in general would decide to have radically fewer children.

Is a change from 7 to, say, 4.5 children over a fifteen-year period a rapid change, as has been suggested by the World Bank study? It all depends on the point of reference. In Europe, the pace of change was slower. In South Korea, Taiwan, and Thailand it was faster. It can be compared to the change that has taken place in Kenya, a fall from over 8 to around 5.3 children in fifteen years (Egerö and Mburugu 1994).

\footnotetext{
I There is good historical evidence, both from Europe during the last century, and from countries in the South during recent decades, that fertility has risen somewhat before the start of real fertility decline (see e.g. Nag 1980, Dyson and Murphy 1985, Egerö 1994). Although the reasons for a rise may vary between societies, it can often be interpreted as a sign of social change that will lead to fertility decline.
} 
Again, it is faster than the trend in Pakistan, and more or less at par with those of the Indian states of Madhya Pradesh and Uttar Pradesh, generally regarded as slow in the Indian context. ${ }^{2}$

To reach a stabilization of the number of people, the fertility level must fall to just over 2 children per woman. In Bangladesh, the figure 4.5 lies pretty well midway between 7 and 2 . However, in a poor farming community an average of 2 children is very low. There are no immediate reasons to expect the trend to continue at the same speed as before, or that it would even reach 2 children per woman.

\section{Differences in the levels and trends of fertility}

The differences in fertility between rural and urban populations have historically been small, but have increased somewhat during the $1980 \mathrm{~s}$. We expect that this is due to the concentration of "white-collar" employees - office workers, those with more than primary education - in the cities. There are also significant differences between different areas of Bangladesh. Regional data from around 1980 show differences from 7 children per woman or more in some coastal subdistricts to below 5 in subdistricts along the eastern border (Mesbah-us-Saleheen et al. 1991).

There are many possible reasons behind such differences. Muslim communities tend to have more children than Hindu. Access to schools and education - generally regarded as a key factor for fertility change - often varies in a country. This variation is itself sometimes an indicator of differences in economic or social conditions. In Bangladesh, however, differences in education cannot explain the regional variation in fertility. On average much less than half the adult men in rural areas have more than a few years of education, and women lag far behind the men. The reduction of fertility with education is seen only with upper primary or higher education.

The 1994 World Bank study scans much of the evidence on social dimensions of reproduction. It reaches the conclusion, that "all major socioeconomic strata have modified their reproductive behavior. The poor, the landless, and the illiterate have reduced their fertility at the same time and to the same extent as the better-off, the landed, and the literate" (Cleland et al. 1994, 57). The data presented in support of the conclusion is weak. Yet, a national fertility average could never change as much as it has without similar changes taking place among the majority of rural poor.

\section{Fertility change and provision of contraceptive services}

Could such changes be the result of family planning efforts alone? This is, essentially, the issue debated today. As it appears, the poor remain poor, the women remain heavily subordinated. What has changed is that provision of contraceptives has improved and more efforts have been given to spreading the message that they can be used to avoid too many pregnancies.

That modern contraceptives, sterilization, etc. are made more widely available is no doubt a change worth investigating. But we must be cautious about any attempt to

\footnotetext{
2 See Das Gupta and Narayana (1995. 6), who dryly comment that "the perception of what is happening in the two settings is diametrically opposed. Analyses of the central Indian states view the fertilify decline to be exasperatingly slow, and conclude that it would be faster if there was more rapid socio-economic development, and if the health and family planning programmes worked more effectively. In the context of Bangladesh, by contrast, the fertility decline is perceived to have been rapid. The decline is attributed to the family planning programme, rather than to socio-economic development."
} 
explain, looking only at this change. Before contraceptive technology was brought to the poor in Bangladesh, quite substantial regional differences already existed in childbearing. Independent studies have provided evidence that the average fertility was rising around the time of the 1960s. Explanations need to be sought for these phenomena, which might have significance also in understanding the more recent changes.

Family planning activities in Bangladesh started already in the 1950s. Initially, they did not yield much effect. It was only in the mid-1970s that more systematic work to spread contraceptive information and services over the country was started. The programs are government-run, in a special organization from central to local levels. This priority accords with the situation in rural areas. According to a general rural poverty study of 1992 , only $13 \%$ of the rural population had access to government health services. By contrast, Cleland et al. (1994) report that in 1991 around $20 \%$ of "currently married women" use such contraceptives which require access to services (primarily pills and injections). Another $10 \%$ had been sterilized.

This level of contraceptive use and sterilization is indeed a change compared to the $4 \%$ and $0.8 \%$, respectively, reported in 1975 . There are however reasons to question whether in fact the reported level of use of contraceptives accords with the reported supply of contraceptives. A small investigation reported in Appendix 1 suggests that the figures on contraceptive use are exaggerated, and that a fall from over 7 to 4.5 children per woman is more than could be explained with the fact that $30 \%$ of the couples in Bangladesh engage in modern birth control.

To give women (and men) access to well-adapted modern contraception is indeed to widen their options in life. Most likely, there is still a long way to go before all people in Bangladesh have access to services, and then, as Cleland et al. point out, the economic, social, and health costs linked to switching from "traditional" methods to pills, IUDs or sterilizations still remains. Fertility has fallen in Bangladesh, partly through the minority which is now using modern contraception or getting sterilized. A majority of couples appear to use other means. The motivation for fewer children must lie elsewhere than in a government-run program for the provision of contraceptives.

\section{What has happened to poverty and landlessness?}

Hard data on poverty are notoriously difficult to get. Historical data rarely refer to more than small samples of a population. For Bangladesh, two entirely different pictures emerge. One is based on health and survival. Available accounts hold that life expectancy at birth, as already mentioned, has increased by more than 30 years since the turn of the century. Thus living conditions must have improved.

The other picture starts from the fact that population numbers and densities have increased rapidly, giving ever smaller space for the individual household. One account, from 1986, suggests that:

"As recently as 50 years ago, some areas of Bangladesh were still in their first generation of settlement; densities were between one-fourth and one-third of present levels, yet agriculture used much the same technology as at present. Rural families owned land and enjoyed a far more comfortable life." (Robinson 1986, 295.)

Between these two lies a third perspective, which holds that nothing much has in effect changed. The Bangladeshi majority has always been poor, always vulnerable to crises. A stable and widespread poverty characterizes Bangladesh more than anything else. Famines are known since the 18 th century - the worst reported to have taken place in 1943. Natural and political hazards continue to plague the poor, killing hundreds of thousands in every disaster (see Figure 3). 
Fig u re 3. Estimated deaths due to disasters in Bangladesh, 1918-1991.

1991

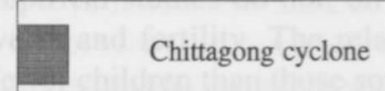

1971

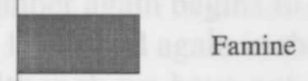

1970

1947

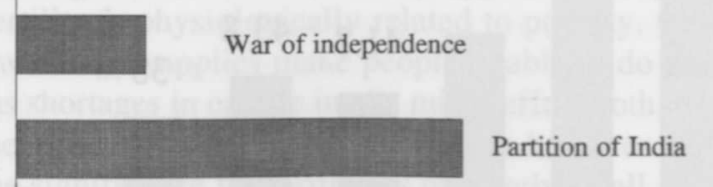

1943

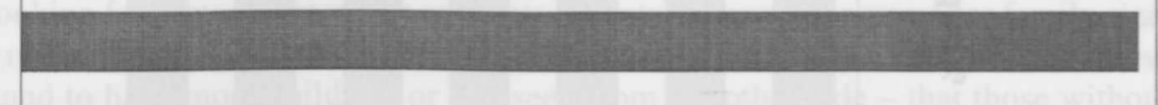

1918

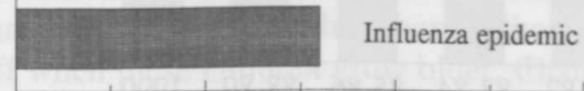

0

1

2

Deaths as proportion of population

Bengal famine

Source: Cleland et al 1994

All three visions hold elements of truth. Modern medicine, improved environmental sanitation and other measures have improved the chances of survival even under conditions of poverty. Little else has happened, and more and more people strive to get their daily survival out of the same land, with the same tools and labor. Improvements in medicine and sanitation have been offset by increasing shortage of land. The net balance could be seen as stagnation.

In the present report, we will avoid getting entangled in discussions about the more distant past, and limit the time scope to the last three decades. Since the partition of India in 1947 no major natural disaster was reported until the cyclones of 1970 . These were followed by the 1971 War of Independence, and again by a major famine in 1974 . Most observers maintain that these crises made the period to the mid-1970s one of worsening economic conditions for the poor. In the $1960 \mathrm{~s}$, women did not participate in the rural works programs because it "...would have been considered a highly visible and demeaning form of labor for them" (Kabeer 1994). In the mid-1970s, many women were forced to seek this kind of work.

Gradually, society recovered from the crisis, and by the end of the 1980 s the proportion of the population living in poverty had come down to what it was in the $1960 \mathrm{~s}$. Today, it might have declined a few percentage points more (see Figure $4^{3}$ ). Thus, rather than living in stable misery, the poor have passed through a period of growing disaster and desperation, which forced people to adapt in ways they would not otherwise have done. This adaptation is a social change which remains even through a period of recovery and means that the society is no longer the same as before.

The growth in numbers of rural households has led to opening up of new land including land that is less accessible or more vulnerable to flooding in the event of nat-

\footnotetext{
${ }^{3}$ Poverty statistics are not strictly comparable during the period, due to changing definitions.
} 
F i g u r e 4. Trends in rural poverty as per uniform method of calculation (per capita expenditure classification).

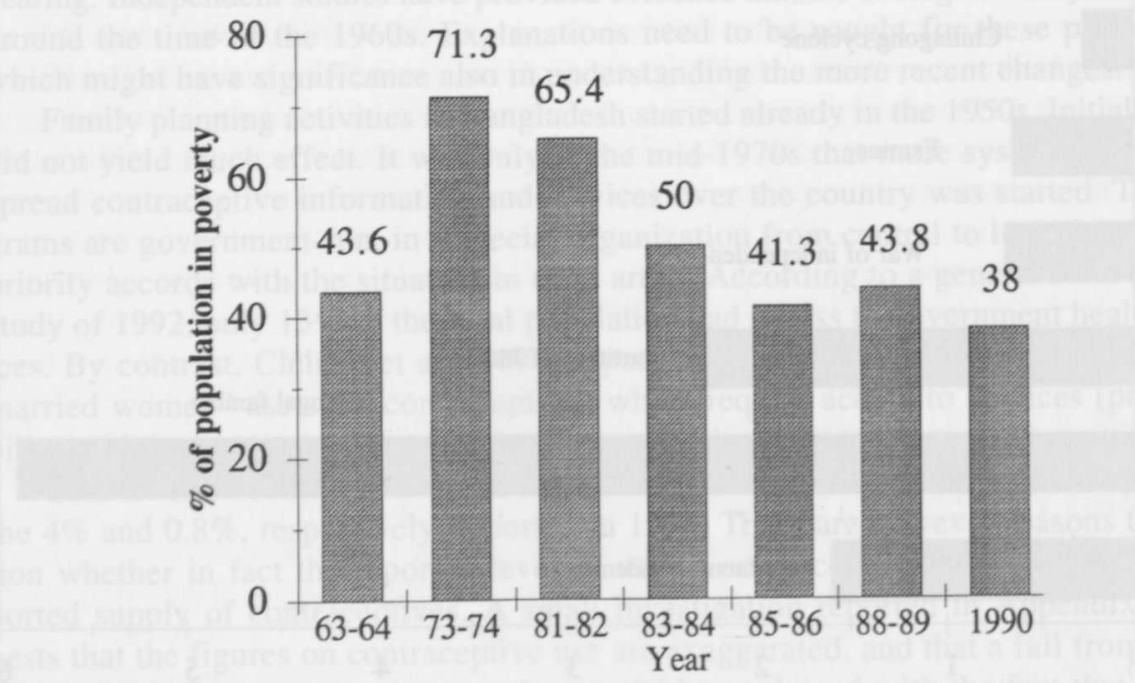

Note: Uniformity of calculation by Binayak Sen

Source: Rahman \& Hossain 1992

ural disasters. At the same time, the average size of landholdings declined for the poor. Although there are no signs of a growing concentration in landownership during recent years, land distribution remains very skewed. At the same time, a considerable exchange in land seems to be taking place. One way is when poor households are forced to sell a piece of land to overcome a temporary crisis. Fragmentation also occurs as new generations of households require land (Chaudhury 1989).

Available statistics (Chisholm 1984, Cleland et al. 1994) indicate that already in the 1970 s around half of all rural households had landholdings too small to be economically viable $(<1 / 2$ acre). These "functionally landless" (which also include those literally landless) are by the end of the 1980 s estimated to have grown to two-thirds of all rural households (Rahman and Hossain 1992).

Labor statistics indicate that the limits of labor absorption in agriculture have been reached. During the period 1961-74 more than half of the new entrants into the labor force went into agriculture. In the period 1974-81 the share of agriculture in fact decreased, while the big increments were found in the occupational groups of trade (32\%) and manufacturing $(22 \%)$. A variety of non-agricultural activities now add to the incomes of the rural poor. For non-farming households they account for well over half of the income (another $22 \%$ comes from employment and wages). But they are important also for farming households, providing about one-third of their income. (Cleland et al. 1994, Table 3.8; Hossain 1994, 41).

The general impression is, that few households survive exclusively on agriculture. The less land a household has, the more other activities support the survival of the household. The eroding agricultural base increasingly pushes people into other sources of survival. Maybe we are now witnessing the spread of artisanship as a first step in a small-scale industrialization of the countryside. The process got a strong push during the crisis years of the $1970 \mathrm{~s}$. It may at least partly have modified the gender-related social institutions of labor division, preventing women from participation in economic activities. 
How is landlessness linked to fertility?

Empirical studies do not, on the whole, show any straight relation between degree of poverty and fertility. The relation is sometimes curvilinear: the poorest of the poor have fewer children than those somewhat better off, while at some higher order of wealth the number again begins to drop. Such a relation has been demonstrated for Bangladesh in the 1960s and again in the late 1980s (Thomas 1991, 384; Cleland et al. 1994, 52).

Although we have not seen any studies of the problem, it seems entirely possible that fertility is physiologically related to poverty. Chronic undernutrition means that the low energy supplies make people unable to do ordinary work (Fogel 1994). Continuous shortages in calorie intake might affect both the frequency of sexual intercourse and the likelihood of conception. There is however evidence (see e.g. Bongaarts 1980) that the significance for fertility is relatively small.

Looking for factors that might motivate parents to search for a smaller family size, some researchers suggest that the need for more hands on the farm stimulates those with land to have more children, or - if seen from the other side - that those without land are unsure about whether sharing their meager lot between more children will pay off when these children grow older. Chaudhury's (1989) data from rural Bangladesh in the 1970 s show that landowning households were larger the more land they had. The relation was strong: per capita land also grew with the size of the household. The landless households were the smallest - less than 5 members on average. Chaudhury concluded that children in fact were a contribution to the acquisition of land.

There are of course possible fallacies in this conclusion. For instance, a newly married couple normally has not yet begun to accumulate resources. The family career may consist of both adding new children to the family and acquiring more land, for instance through inheritance. Where more healthy children are born, they will become an asset in the utilization of the land. Another fallacy is that Chaudhury does not always distinguish nuclear families from extended family households. It is perfectly possible that the extended family is stronger in situations where the oldest generation has good access to land. ${ }^{4}$

Mead Cain, who has done much valuable work on reproduction and the roles of children in Bangladesh, has warned against the interpretation that for a landless household few children is a result of choice. In Cain's view, "The environment of risk was so generalized and endemic in Bangladesh society and alternative institutions to the family as a form of insurance... so inadequate that families from all classes had a strong incentive to aim for a target of at least two surviving sons..." (various reports by Cain, summarized by Kabeer 1994, 128). If landless families had fewer children, it could be caused by other factors, for instance that husbands were away for long periods in search of work.

Other studies of both urban and rural poor (Caldwell et al. 1984; 1992) found that there was an economic rationale for large families among wealthier households, but "For rural landless and urban poor, high fertility brings less gains and so fertility would decline if barriers to contraception were lessened" (Kabeer 1994, 129).

\section{What has happened to the situation and status of women?}

A serious treatment of women's lives and gender relations in Bangladesh requires more space than is available in this context. There is no doubt that the subordination

${ }^{4}$ In a personal communication, Monica das Gupta points at numerous evidence from South Asia that the wealthy households tend to remain intact and therefore have larger household size than the poor. 
of today has deep historical roots. A writer from the last century has likened the existence of Bengali women to that of "birds in a cage" (see Adnan 1993). The analogy seems justified: Their lives is regulated through the cultural institution of parda (or purdah), according to which women should be isolated from contacts with all men outside of their immediate family and near relatives. Women should remain in their homes. They are permitted to move to "indoor" spaces of other prescribed households, but not to "outdoor" spaces. The latter are the public and male spheres of life (ibid.).

In practice, this circumscribes women's lives in various ways. In strict adherence to parda, they cannot undertake work outside their home, but do a variety of work at home, including post-harvest processing of crops. The young girls are supposed to stay in the custody of their family until they are married off and move to the shelter of their husband's house. They remain subordinated to men throughout their lives - father or brother, husband, son. They are not permitted to make their own decisions, in particular not on matters which go beyond the internal affairs of the home.

There is today no agreement on how far parda still regulates the life of women. That urban middle-class women live under more relaxed conditions is likely, but in the rural areas the situation probably varies a good deal. Two factors may account for this. First, what could be called "modernization" reaches some parts of the countryside faster, and with more impact, than other parts. For instance, roughly one-tenth of Bangladeshi villages have access to electric power. Grameen Bank, a credit facility with poor women as its main clients, had operations in nearly half of all villages in 1994. But studies show that in some areas, for instance in the north (Amin 1994), the institution of parda still puts serious limits to women's work in "outdoor" spaces.

The other factor is the force of necessity. Social customs such as parda can be successfully maintained where economic conditions improve, as is the case in Saudi Arabia. But when desperation befalls a family and their direct survival is threatened, then social institutions such as the Bangladeshi gender division of labor may lose their importance. Those most likely to violate the institution are the poorest, those who have little social prestige to defend and are worst stricken by hardships.

The impression from various studies of Bangladesh is that the hard years of the 1970 s forced many rural households to reconsider the customary labor division. We have already referred to how in the 1970 s women went in search for jobs that a decade earlier were considered demeaning. We have also shown that manufacturing and trade occupations became more common during this period as alternative sources of income. Such was the stress, that extended family structures in part gave way to nuclear families:

"By the mid-seventies, it had become evident that those with little land to bind them together were most likely to split up into atomistic nuclear units and that in situations of extreme poverty, landless households disintegrated further so that elderly parents were separated out from their adult son and his wife and forced to beg or else children would be sent away to work as servants" (Adnan 1990 summarized by Kabeer 1994, 139).

During the 1980 s, women have continued to search for work outside the home to add to the family income. Official statistics shows that such work is still fairly infrequent. However, a microstudy of four villages in 1985 found that there had been a rise in female employment in the whole subdistrict or upaliza since the mid-1970s. In the villages, women in between 8 and $20 \%$ of the households went in search of wage employment. Among landless households the figure rose to 50-77\% (Rahman 1986). Two general surveys from 1985/86 and 1989/90 confirm this: Female participation rates by age were a stable 5-10\% in the earlier, and (for women $25-50$ years), 15-20\% in the latter period (Hamid 1992, Figure 1).

There are other signs that the situation of poor women is changing. They no long- 
er marry as early as before. In 1961 , close to $90 \%$ of all women aged 15 to 19 years were married. Towards the end of the $1980 \mathrm{~s}$, less than half were married, and the level of $90 \%$ was reached only in the age group 25-29 years (Cleland et al. 1994, 26). Women are more mature, they may have had a chance to go to school or at least to learn to read and write, before moving to the home of their husband.

The age difference between the spouses is regarded as an important indicator of patriarchy - men's control over their women. In 1961, the age difference between husband and wife was 9 years on average (ibid.). Although men are also marrying at higher ages now, the gap has closed somewhat. The mean age difference in 1989 was 7.5 years.

The majority of all women still cannot read or write. But there is an improvement worth noting: During the 1980 s the proportion who were literate among females 5 years or older increased from $16 \%$ to $29 \%$ (Hamid 1992, 148). This change most likely reflects the fact that girls can now at least start their education more often than before even if many leave before finishing their third year. According to official figures, school enrollment has increased during the $1980 \mathrm{~s}$, and more so for girls than for boys (see Table 1).

T a b le 1. Percent enrolled in school within age groups

\begin{tabular}{llll} 
5-9 years: & Both sexes & Boys & Girls \\
1974 & & & \\
1981 & 18.7 & 22.0 & 15.4 \\
1991 & 22.5 & 24.7 & 22.2 \\
$10-14$ years: & 41.0 & 42.3 & 39.6 \\
1974 & & & \\
1981 & 33.8 & 40.5 & 25.8 \\
1991 & 33.3 & 37.9 & 28.1 \\
\hline & 54.2 & 55.9 & 52.3
\end{tabular}

Cleland et al 1994, 70.

The 1980s was also the period when the Grameen Bank and BRAC (Bangladesh Rural Advancement Committee) expanded their activities over Bangladesh. They are the two most important of a growing number of credit programs for poor women. Grameen Bank did not initially direct itself to women. Soon, however, it found that they were the most reliable credit takers. Currently, the Bank has 1.5 million women members and, as already mentioned, is working in about half of all villages in Bangladesh (Schuler and Hasemi 1994).

1.5 million is still a small figure compared to the 25 million or so eligible women in Bangladesh. What is perhaps most interesting about Grameen Bank is that it has, in fact, managed to enlist so many women, in so many different places, as members. This alone is a sign that parda is no longer so strictly adhered to.

Membership in Grameen Bank, or in other credit programs, is in itself a source of empowerment by strengthening the economic role women play in the household. The Bank practices a system of local weekly meetings, which gives women socially legitimate reasons to move outside their homes, and to meet others in public places. In the meetings, women can exchange and learn about new ideas All this goes to strengthen their self-confidence.

\section{So what makes fertility decline among the poor in Bangladesh?}

The 1994 World Bank study of reproductive change in Bangladesh is, on the whole, an emphatic plea for more contraceptive services and information/education on the value 
of a small family. Having scanned a variety of indices on material change or other sources of change in people's demand for children, the main conclusion drawn by the authors is that improved contraceptive supplies and services have succeeded - more women use modern contraception and therefore fewer children are born.

Nevertheless, the report admits to some problems in its analysis. As it rejects any significant influence of other changes on the demand for children, the idea of "latent" demand' is correspondingly important in its final conclusions. The expectation that there exists a "latent demand" for contraception is based on the fact that more children survive today than 50 or 100 years ago. But, the authors say, demand is fragile and weakened by underlying ambivalence. It has to be nurtured. The rates of discontinuation of contraceptive use are high, and therefore intensive outreach is necessary.

The Bank report maintains that contraceptive knowledge is nowadays universal, that supply exists and that the desire for small families is widespread. Why then is it necessary to have a complex and resource-demanding program to make people use the contraceptives? Answering, the report seemingly contradicts some of its earlier interpretations:

- It is likely that the desire for small families is offset by enduring high fertility norms and values;

- the social, psychological, and monetary costs of contraception can be unacceptably high;

- the parda - female seclusion - severely constrains women from attending clinics;

- finally, "the advent of a marginal extra child does not make a huge difference to many families" (ibid., 134).

Again, looking back at its findings, the report finds that life in Bangladesh villages has hardly remained static over the past 20 years:

"Farm sizes have diminished, and many more families are now functionally landless. This trend has been accompanied by a major shift in labor force composition away from agriculture and toward a greater diversity of livelihoods. There has probably been a growth in multiple sources of income for households and a partial breakdown in traditional patron-client relationships. Economic life has become more complex, more monetized, and perhaps more volatile. Villages have become less isolated. They are now more likely to be linked to the outside world by the mass media, by motorized transport, by temporary migrants to towns and cities, and by the intrusion of a myriad of nongovernmental organizations. Though these changes have not yet brought growing prosperity, their collective impact represents an element of modernization, with unknown, but perhaps profound, effects on outlooks and expectations. It is unlikely that family planning would have flourished in the absence of all these other changes" (Cleland et al. 1994, 133, emphasis added).

The image of Bangladesh rural life as essentially static, economically as well as socially, has been spread internationally over the last few years in debates over fertility decline and its causes. Not only The Washington Post (Mathews 1994), but also Scientific American (Robey et al. 1993) have subscribed to this picture and defended the thesis that investments in contraceptive supplies and services - projects referred to as family planning programs - will do the work even in the absence of development.

They are only in a very limited sense correct in stating that economic improvement is by and large absent from the lives of the poor majority in Bangladesh. Although poverty measures are notoriously difficult to compare, the changes in women's access to education and economic activities summarized in the above quote are by themselves significant ingredients in socioeconomic change. Expanded perspectives are part 
of the empowerment of women, through which rising expectations give new perceptions of problems and possible solutions, among them to have fewer children.

\section{How does Bangladesh compare with other countries?}

In Bangladesh it is mainly older women, with five or more children, who nowadays choose to postpone the next pregnancy or cease childbearing altogether (Cleland et al. 1994; Amin 1994). A similar pattern is found in the Indian state of Tamil Nadu (Kishor 1994). It can be seen as a response to the fact that children survive today in a way they did not for earlier generations. It is also a sign that women's lives have changed. They participate more in activities outside the house, some of them manage to find work for money, and a new child is not only a temporary obstacle to their work but also a new member of the house the cost of whom can be measured in money.

In a study of the Indian state of Punjab, Monica Das Gupta (1994) has shown that in the old days peasants were striving for an optimal number of children - more to replace household members lost during a period of crisis, and less when labor needs were satisfied again. But sudden mortality crises left a deep impact on peasant societies, which took long to dissolve. Only "The second generation of people who lead a secure, ordered life do not experience the anxieties left over from past insecurities" (das Gupta 1994, 119). The poor in Bangladesh experienced their latest major disaster a little over twenty years ago - one generation back. Today's parents were themselves children at the time. Continued stability in their lives undoubtedly is an important precondition for the trend towards smaller families to continue.

Kenya is a land seemingly different from Bangladesh in all possible respects. It has a much smaller population on a much larger area, it is more urbanized and has a more diversified economy. The culture - or cultures - are different. But there are some interesting similarities. One is the growing lack of land for farming. Like in Bangladesh, most Kenyans still depend on smallholder agriculture. But large areas of Kenya are either alienated from the smallholders, or unsuitable for cultivation. There is no more land for the new generations. More and more rural households are functionally landless in the same sense as in Bangladesh. The households need to find new sources of income, and their children may have to leave agriculture altogether (Egerö and Mburugu 1994).

A rapidly growing proportion of Kenyan women have been to school. One aspect of their empowerment is that they try to gain better control over their reproduction, including a better spacing between pregnancies. The same tendency is found among women in Bangladesh. Modern contraception is a valuable support, and more socially acceptable today than a decade ago.

A similar development has taken place in Zimbabwe. Since independence in 1980, girls have enrolled in primary school almost universally. Women have strengthened their positions in the local rural communities. Their men, many of them labor migrants since the colonial period, have found it increasingly difficult to maintain their wage employment. Finally, in regions called communal areas to which small farmers are still restricted, population increase and hunting for more land means that land is in very short supply. Where would the young with their education go, when neither urban employment nor a dynamic agricultural sector is there to provide them with jobs?

As the women become increasingly responsible to keep the family going, fewer children is a rational answer. A well functioning contraceptive supply service without strong elements of persuasion helps them in their choice. In Zimbabwe like in Kenya, the motivation for fewer children is also bolstered by an increasing uncertainty about 
whether the children will really be there to support their parents in old age. Children need clothing, they need education. But even the educated children often fail as adults to get incomes with which they can - or want to - give their parents good financial support. $^{5}$

This sense of uncertainty about the long-term returns of many children is heard in many different countries. It was recorded in the Matlab area in Bangladesh. Duza and Nag $(1993,74)$ found among parents a growing "skepticism about the long-range value of investing in children", because children cannot even support themselves, or will have to migrate in search of jobs. If children can no longer be counted on to take care of their old parents, one important reason for many children is beginning to fade away.

China has experienced a remarkably rapid change over to small families. Within a few decades, the number of children born per woman has fallen from over 7 to about 2 children. For many, this shows the determination of the Chinese government to reduce childbearing in the interest of an earlier stabilization of population numbers, and what can be achieved through the use of unscrupulous methods and modern contraception. Interestingly enough, however, the same rapid fertility decline has taken place in other parts of the Chinese cultural area - Hong Kong, Singapore, South Korea, Taiwan - without the administrative force exercised in China (Caldwell 1993).

In all of these cases, other important changes have taken place which have fundamentally changed the conditions under which people live. A social security has been established, an absence of crises whether from nature or from wars and plunder. Health systems have been erected, and education has been made universal. Old-age security is at least to some extent taken care of outside of the family. And, last but not least, women have seen their situation improve - women become wage earners, women work on the farms, women have an active role in decision making.

Security and confidence are important conditions of a change to smaller families. Evidence can be found not only in Asia. In Costa Rica in the decades after World War II, poverty and insecurity were tackled through welfare-oriented politics during a period of successful industrialization and increasing export. A system of social insurance was developed over the country, first among wage employees, later to other sectors. One result was that fertility fell, in all social groups. A remarkable decline occurred among the poor - women with less than 4 years of education had on average 9 children up to 1965. Ten years later, this figure had fallen to below 5 (Dierckxsens 1994).

The trend was, however, not yet stabilized. With the economic crisis around 1980, the poor were particularly affected, and childbearing went up again. A period of difficult social adjustment followed, marked by marriage breakups and the birth of many unwanted children. Gradually the poor women began to face up to the new situation, where they had to trust themselves more than the government or their (unemployed) men. Many started to make an income in the informal sector, and the interest in fertility control grew. Over time, fertility resumed its decline.

\section{Gender relations and fertility change}

In all the cases cited, changes in childbearing have been accompanied by other changes in the lives of poor people. They have not necessarily become much richer.

5 These observations support Caldwell's theory (1982) that fertility levels and trends can be interpreted as reflecting (changes in) intergenerational wealth flows between parents and their children. In modern Europe where fertility is low, parents generally pay for the upkeep of their children until they are adults, not expecting - and normally not getting - any financial returns. 
But social relations have changed, in particular relations between the sexes. The postwar era is an era of rapidly increasing contacts. Distant villages are no longer isolated. They are reached by new information through schools, migrants, radio, TV. A myriad of NGOs have spread over the countryside of poor countries, influencing perceptions and behavior.

Transition was there even under a colonial power, but kept more restricted in the interest of colonial rule. The movement towards independence was a radical and allembracing phase in the transition. Some countries may have tried to resurrect their old traditions, but no one has resisted the influence of technology, movements, ideas. Everywhere, gender relations of subordination of women have come under strain.

John Caldwell and his colleagues have noted that in West Africa the market provision of contraceptives is important for many categories of consumers (Caldwell et al. 1992). They are men in all ages, married or not; older couples who according to customs are not supposed to engage in sex; and single women. This de facto openness of the system should be seen in the light of women's position in the market: women are traders, they control the stalls and the local markets, they engage in negotiations and deals. Still, fertility is falling slowly or not at all. Other studies from West Africa present a picture of relatively high consciousness among women about their childbearing, a choice of fertility in line with what serves their own interests.

The point about such observations is that more equality in gender relations does not in itself generate a decline in fertility. Women may choose to have many children or few, depending on their social and economic situation. A high level of fertility cannot automatically be interpreted as evidence of subordination of women.

Generally, however, when women get more say over their lives they also tend to have fewer children. Women carry the burden and the costs of childbearing, with their health and labor. They will always strive to have a fair period of recovery between pregnancies, and they will want to avoid many pregnancies. In many cases, the changes going with "modernization" have also led to a weakening or loss of controls of the spacing between pregnancies (e.g. shorter periods of breastfeeding). Women's empowerment should also be seen to include better ability to avoid unwanted pregnancies. Modern contraception is one of the means they will want to use.

When fertility falls in Bangladesh and in Kenya, the same factors could very well be behind the change. In both cases, women are getting more power, more say over their lives. This empowerment leads to lower fertility, simply because women strive to maintain or restore a reasonable period between pregnancies, and they increasingly stop after having had many children. They also engage more and more in work outside the house, which leads them to reevaluate the costs and benefits of an additional child. Finally, women in both countries become increasingly unsure about what to expect from their children as they grow old, especially as land is no longer available and the children may have to migrate in search of employment.

Although as yet little explored, there are signs that in Kenya a process of nuclearization is underway, where more of decision making takes place within the family and parents-in-law have less to say about the wife's childbearing. Similar signs are reported from Bangladesh. Their extent and significance for reproduction are still mainly a matter of opinion.

\section{Concluding comments}

There is no doubt that development in poor countries today is heavily influenced by external interventions. Where these interventions lead depends on how they inter- 
act with local culture, history, and traditions. A demographic transition is a type of development which leaves no one untouched, which in fact depends on the participation of the smallest units of production and reproduction in society, the individual families. Unlike many high-technology development projects, whose direct impact on people may be marginal, the demographic transition as a project of change requires adherence to the needs of people. Development support in this context aims at a satisfaction of their needs simultaneously with a reduced material dependence on children in the family.

It is obvious, that no one single development intervention can have such aims. The different interventions must be guided by a common perspective, which in the present context could be found in the following direction:

a. Security is an essential dimension of the poverty complex. For the Bangladeshi small farmers, like for their counterparts in Punjab, safety first is a principle grounded in a historical environment of unanticipated crisis - natural disaster or human destruction. Security has another dimension as well - the survival of children and adults. High child mortality and high relative risks that disease will strike an adult are difficult problems in a resource-poor household. In both these respects, lack of security contributes to keeping fertility up.

b. Choice is another dimension. Poor people are by their poverty constrained from access to different options to improve their lot. One constraint is in the lack of knowledge and of information. Another is embedded in the social norms regulating gender relations, for instance. In Bangladesh women were held back from contributing to the family economy even in very poor households. The extreme stress of the 1970 s, and the existence of employment-generating projects and other changes in the environment, forced some changes in their subordination. Today, many women have improved their conditions for choosing and deciding - on production and consumption, and on reproduction.

c. Economic opportunities within reach of the poor are a necessary vehicle of change. The Green revolution has changed the lives of millions of poor in India and paved the way for a change to smaller families. The Grameen Bank and similar initiatives in Bangladesh are important not least for the stimuli they give to economic initiatives, however small and fragile. The mere perception that opportunities exist could be seen as a real social change in the lives of extremely poor communities.

d. Attention to the most exposed is, for lack of a better phrase, how one could formulate a dimension much talked about but about which is little done. The most exposed are, first and foremost, women: the widow losing the land she had no rights to (or even losing land she did have rights to), the childless woman left divorced and without security. Legal reforms which are followed up in practice, land control and distribution so that even the poorest can produce for their own subsistence, are part of this attention. Functioning health services attending to the reproductive health needs of women, including advice on fertility regulation, are equally important.

e. Labor market expansion and absorption of new entrants is a key factor in an economy with high rates of population increase. Where the options for expansion of the small farm sector are constrained by lack of land, labor-demanding intensification is essential, as is artisanship and rural industrialization. Beyond providing young people with employment, this development changes the whole context within which reproductive decisions are made, stimulating a switch to "quality" - fewer and better educated children with better chances on the labor market. 


\section{Acknowledgements}

The author extends his special thanks to Mikael Hammarskjöld, PROP, for his assistance.

\section{References}

Adnan, S. 1990. Annotation of Village Studies in Bangladesh and West Bengal: A Review of SocioEconomic Trends over 1942-88. Bard: Comilla.

Adnan, S. 1993. 'Birds in a cage': Institutional change and women's position in Bangladesh. In: Women's Position and Demographic Change, edited by Federichi, N. et al., pp. 285-317. Oxford: IUSSP, Clarendon Press.

Amin, S. 1994. The Poverty-Purdah Trap in Rural Bangladesh: Implications for Women's Roles in the Family. Paper presented at IUSSP seminar on Women, Poverty and Demographic Change, Oaxaca, Mexico, 25-28 October 1994, mimeo.

Bauer, J. and A. Mason. 1993. Equivalence scales, costs of children, and poverty in the Philippines and Thailand. In: Fertility, Family Size and Structure, edited by Lloyd, C.B. New York: Population Council.

Birdsall, N. 1988. Economic approaches to population growth. In: Handbook of Development Economics, edited by Chenery, H. and T.N. Srinivasan. Amsterdam.

Bongaarts, J. 1980. Does Malnutrition affect fecundity? A summary of evidence. Science Vol. 208(4444):564-9.

Cain, M. 1983. Fertility as an adjustment to risk. Population and Development Review 9(4):688-702.

Cain, M., S.R. Knanum and S. Nahar. 1981. Risk and insurance: Perspectives on fertility and agrarian change in rural India and Bangladesh. Population and Development Review 7(3):435-474.

Caldwell, J.C. 1982. Theory of Fertility Decline. London: Academic Press.

Caldwell, J.C. 1993. The Asian fertility revolution: its implications for transition theories. In: The Revolution in Asian Fertility. Dimensions, Causes, and Implications, edited by R. Leete and I. Alam. Oxford: IUSSP, Clarendon Press.

Caldwell, J.C., A.K.M. Jalaluddin, P. Caldwell and W. Cosford. 1984. The Changing Nature of Family Labour in Rural and Urban Bangladesh: Implications for Fertility Transition. Canadian Studies in Population 11(2).

Caldwell, J.C., I.O. Orubuloye, and P. Caldwell. 1992. Fertility decline in Africa: A new type of transition? Population and Development Review 18(2):211-242.

Chaudhury, R.H. 1989. Population pressure and its effects on changes in agrarian structure and productivity in rural Bangladesh. In: Population Growth and Poverty in Rural South Asia, edited by Rodgers, G. New Delhi: ILO and Sage.

Chisholm, N. 1984. Who's Rural Development? Socioeconomic Change in DTW (Deep Tub Well) Pumgroups in Boya District, Northwest Bangladesh. Dhaka: SIDA.

Cleland, J., J.F. Philips, S. Amin, and G.M. Kamal. 1994. The Determinants of Reproductive Change in Bangladesh. Success in a Challenging Environment. World Bank Regional and Sectorial Studies. Washington: World Bank.

Coale, A. 1973. The Demographic Transition. In: International Population Conference, Liège, 1973, IUSSP, Vol. 1, pp. 53-72. Liège: IUSSP.

Das Gupta, M. 1994. What motivates fertility decline? A case study from Punjab, India. In: Understanding Reproductive Change, Kenya, Tamil Nadu, Punjab, Costa Rica, edited by Egerö, B. and M. Hammarskjöld. Lund.

Das Gupta, M., and Narayana, D. 1995. Bangladesh's Fertility Regime from a Regional Perspective. Center for Population and Development Studies, Working Paper 95-02. Harvard University.

Dierckxsens, W. 1994. Costa Rica - The unfinished demographic transition. In: Understanding Reproductive Change, Kenya, Tamil Nadu, Punjab, Costa Rica, edited by Egerö, B. and M. Hammarskjöld. Lund.

Duza, M.B. and M. Nag. 1993. High contraceptive prevalence in Matlab, Bangladesh: Underlying processes and implications. In: The Revolution in Asian Fertility. Dimensions, Causes, and Implications, edited by R. Leete, R. and I. Alam. Oxford: IUSSP, Clarendon Press.

Dyson, T. 1991. Child labour and fertility: An overview, an assessment, and an alternative framework. In: Child Labour in the Indian Subcontinent, edited by Kanbargi, R. New Delhi: Sage.

Dyson, T., and Murphy, M. 1985. The Onset of fertility transition. Population and Development Review 11(3):399-440. 
Egerö, B. 1994. Reproductive change is a social process. In: Understanding Reproductive Change, Kenya, Tamil Nadu, Punjab, Costa Rica, edited by Egerö, B. and M. Hammarskjöld. Lund.

Egerö, B. and M. Hammarskjöld (eds.). 1994, Understanding Reproductive Change, Kenya, Tamil Nadu, Punjab, Costa Rica. Lund.

Egerö, B. and E. Mburugu. 1994. Kenya: Reproductive Change under Strain. In: Understanding Reproductive Change, Kenya, Tamil Nadu, Punjab, Costa Rica, edited by Egerö, B. and M. Hammarskjöld. Lund.

Feldman, S. 1992. Crisis, Islam, \& gender in Bangladesh: The social construction of a female labor force. In: Unequal Burden, edited by Benería L. and S. Feldman. Westview Press.

Fogel, R. 1994. The Relevance of Malthus for the study of mortality today: long-run influences on health. mortality, labor force participation, and population growth. In: Population Economic Development and the Environment, edited by Lindahl Kiessling, K. and H. Landberg. Oxford University Press.

Ghimire, K.B. 1993. Linkages between Population, Environment and Development. Case Studies from Costa Rica, Pakistan and Uganda. Geneve: UNRISD.

Greenhalgh, S. 1990. Towards a political economy of fertility: Anthropological contributions. Population and Development Review 16(1):85-106.

Hamid, S. 1992. Gender dimension of poverty. In: Re-thinking Rural Poverty. A Case for Bangladesh, edited by Rahman, H.Z. and M. Hossain. Dhaka: Bangladesh Institute of Development Studies.

Henry, L. 1961. Some data on natural fertility. Eugenics Quarterly 8:81-91.

Hossain, M. 1992. Structure and Distribution of Household Income and Income Dimensions of Poverty. In: Re-thinking Rural Poverty. A Case for Bangladesh, edited by Rahman, H.Z. and M. Hossain. Dhaka: Bangladesh Institute of Development Studies.

Kabeer, N. 1994. Re-Examining the 'Demand for Children' Hypothesis in the Context of Fertility Decline in Bangladesh. CDR Working Paper 94.6, Poverty Reduction and Development Cooperation. Copenhagen: Center for Development Research.

Kishor, S. 1994. Fertility Decline in Tamil Nadu. In: Understanding Reproductive Change, Kenya, Tamil Nadu, Punjab, Costa Rica, edited by Egerö, B. and M. Hammarskjöld. Lund.

Mathews, J. 1994. Population control that really works. The Washington Post, 10-04-1994.

Mesbah-us-Saleheen, A, H.M. Raihan Sharif and S.M. Monzurul Huq. 1991. Fertility patterns and socioeconomic development in Bangladesh. In: The Geographical Approach to Fertility, edited by Bähr, J. and P. Gans. Kiel: Kieler Geographische Schriften.

Nag, M. 1980. How modernization can also increase fertility. Current Anthropology 21(5) October.

Oppenheim Mason, K. 1992. Culture and the fertility transition: thoughts on theories of fertility decline. Genus XLVIII(3-4):1-14.

Rahman, R.I. 1986. The Wage Employment Market for Rural Women in Bangladesh. Research Monograph No.6. Dhaka: Bangladesh Institute of Development Studies.

Rahman, H.Z. and M. Hossain (eds.). 1992. Re-thinking Rural Poverty: A Case for Bangladesh. Dhaka: Bangladesh Institute of Development Studies.

Robey, B., S.O. Rutstein and L. Morris. 1993. The fertility decline in developing countries. Scientific American, December 1993.

Robinson, W.C. 1986. High fertility as risk insurance. Population Studies 40(2): 289-298.

Rodgers, G. (ed.). 1989. Population Growth and Poverty in Rural South Asia. New Delhi: ILO and Sage.

Schuler, S.R. and S.M. Hasemi. 1994. Credit programs, women's empowerment, and contraceptive use in rural Bangladesh. Studies in Family Planning 25(2):65-76.

Tai-Hwan, K. 1993. Exploring Socio-Cultural Explanations od Fertility Transition in South Corea. In: The Revolution in Asian Fertility. Dimensions, Causes, and Implications, edited by R. Leete and I. Alam. Oxford: IUSSP, Clarendon Press.

Thomas, N. 1991. Land, fertility, and the population establishment. Population Studies 45(3): 379397.

Thomas, N. 1993. Economic security, culture and fertility: A reply to Cleland. Population Studies 47(2):353-359.

UNDP (United Nations Development Programme) 1994. Human Development Report 1994. New York: UNDP.

UN (United Nations). 1994. Urban Agglomerations 1994. Department for Economic and Social Information and Policy Analysis. New York: United Nations.

Wrigley, E.A. 1969. Population and History. London: World University Library.

World Bank 1983. World Development Report 1983. Oxford University Press.

World Bank 1984. World Development Report 1984. Oxford University Press. 


\section{Appendix 1.}

\section{Contraceptive supply, contraceptive users and fertility regulation}

Statistics are not always foolproof. Data on users of modern contraception suffer from various shortcomings, some of them related to the turnover of users and the problems of distinguishing number of users from number of visits to, for instance, a clinic. To get an indication of the quality of data presented in the 1994 World Bank study of Bangladesh (Cleland et al. 1994), we have checked user statistics against data on the supply of contraceptives.

First, we need an idea about the number of couples, or women, to be served. Virtually all women in Bangladesh marry, most of them at an early age. Some are divorced, others become widows. A reasonable estimate is that $85-90 \%$ of all women between 15 and 49 years are married. This makes, in 1990, about 24 million married women in fertile ages. In about $10 \%$ of the couples, one partner is sterilized. Thus 21.6 million married women remain ${ }^{6}$. Cleland et al. give figures for 1989 , on use as well as on supplies. In that year $9.6 \%$ of the married women used pills. Thus over 2 million women needed a monthly package of pills. Injectables are used by $0.6 \%$ or close to 130,000 women.

On the supply side, in 1989-90 the family planning program had access to about 2,700 service facilities, approximately one for every 8,000 women. These distributed 34,000 cycles of pills, sufficient for only $1.4 \%$ of the women. A total of 126,000 "injectables" were provided. If this figure represents the total number of injections in a year, it is roughly equal to one quarter of the need, given that women need four shots a year. ${ }^{7}$

Judging from the above statistics, the supply side is still far from being able to serve the reported number of women users continuously. Does this mean that user data are exaggerated? Would a better consistency be achieved if the turnover of women users were also recorded? Many observers hold that discontinuity of contraceptive use is frequent in Bangladesh. Cleland et al. $(1994,37)$ summarize the fragmented evidence: "The general impression is that about half of couples who start a method terminate use in the first year. .... large proportion of those who stop do not switch to another method and thus become exposed to the risk of an unwelcome pregnancy". They may, of course, also stop because they want another child.

This possibility is implicit in Cleland et al., when they discuss breastfeeding. Women who breastfeed regularly and frequently are protected for hormonal reasons. Breastfeeding patterns seem quite stable in Bangladesh, at least in duration over time. There are indications that some women use modern contraception to extend the protection from breastfeeding and prolong the period between pregnancies. However, the whole area of choice and options as seen from the side of the women themselves is sadly neglected in research on family planning in Bangladesh.

A theoretical calculation was made to estimate the possible effects of reported sterilization and contraceptive use on a national average moving from 7 to 5 children per woman in 1989. It gave the following result. Judging from Cleland et al.'s statistics from the mid-1980s, the approximately $10 \%$ sterilized couples have on average 4 chil-

8 To simplify the discussion we will not consider the existence of involuntary childlessness

7 We assume that contraceptives are also distributed commercially and/or by private organizations outside the national family planning program. These channels are not mentioned, however, by Cleland et al., which we see as an indication of such supplies not being on a scale that could influence aggregate fertility trends. 
dren. If we, to really press the case, assume that the recorded $14 \%$ contraceptive users have no more than 2 children per woman, then the remaining $76 \%$ end up with 5.7 children per woman. On a more likely assumption of 5 children for contraceptive users, the $76 \%$ not using contraceptives would reach an average of 5.1 children per woman. Thus, the reported fertility fall from 7 to 5 children would not have been possible if women not registered as contraceptive users had continued to have 7 children on average. 